\title{
Nutritional Status at 2 Years in Former Infants with Bronchopulmonary Dysplasia Influences Nutrition and Pulmonary Outcomes During Childhood
}

\author{
LUCILE BOTT, LAURENT BÉGHIN, PATRICK DEVOS, VÉRONIQUE PIERRAT, RÉGIS MATRAN AND FRÉDÉRIC GOTTRAND
}

Department of Pediatrics [L.B, L.B, F.G], EA 3925 IFR 114, Neonatology Unit [VP], Department of Statistics [P.D], Jeanne de Flandre University Children Hospital and Faculty of Medecine, Lille, 59037, France; CIC-9301-INSERM-CHU [L.B, R.M, F.G], Clinical Research Center, Lille, 59000, France; Department of Clinical Physiology [R.M], INPRT, IFR M4, CHU and University Lille-2, 59037, France

\begin{abstract}
Improved survival rates for extreme prematurity have been accompanied by an increase in the incidence of bronchopulmonary dysplasia (BPD). The objective of this study was to assess factors associated with long-term nutritional and pulmonary function outcomes. The study was a cross-sectional study of 52 children who had been born prematurely, had experienced BPD, and were 4-8 y old at the time of the study. Undernutrition was defined as a $Z$ score for weight-for-height of $<-2$ SD. Body composition and lung function were evaluated. Resting energy expenditure (REE) was measured using indirect calorimetry. Stepwise logistic regression was used to test for factors associated with undernutrition and pulmonary function. Eighteen children $(35 \%)$ with BPD, predominantly girls, were undernourished. Undernutrition occurred within the first months of life and was associated with high REE. Multivariate analysis showed that factors significantly associated with undernutrition were female sex and undernutrition at age $2 \mathrm{y}$. Thirty-one children $(60 \%)$ had abnormal lung function tests. Multivariate analysis showed that undernutrition at age $2 \mathrm{y}$ was the only factor associated with the risk of developing distension of the airways. Nutritional status at age $2 \mathrm{y}$ in children who had BPD in infancy influences nutritional and pulmonary outcomes in childhood. (Pediatr Res 60: 340-344, 2006)
\end{abstract}

$\mathrm{N}^{\circ}$ orthway et al. (1) first identified BPD in preterm children with severe respiratory disease treated with mechanical ventilation in 1967. In the past decade, significant advances in the treatment of prematurity have contributed to an increased survival of extremely premature infants (2). The incidence of BPD has decreased in preterm infants born after $28 \mathrm{wk}$ PMA with a birth weight exceeding $1200 \mathrm{~g}$, but still occurs frequently in extremely preterm children (2). Progress in neonatal intensive care has improved the survival rates for extreme prematurity, but has also resulted in a concomitant increase in the incidence of BPD (2). Children with BPD often experience growth failure and chronic lung disease during their first $2 \mathrm{y}$ of life (2). BPD (oxygen requirement at $28 \mathrm{~d}$ or $36 \mathrm{wk}$ PMA) is considered a good predictor of rehospitalization for respira-

Received November 16, 2005; accepted May 5, 2006.

Correspondence: Frédéric Gottrand, M.D., Ph.D., Unité de Gastroentérologie, Hépatologie et Nutrition, Clinique de Pédiatrie, Hôpital Jeanne de Flandre, 2 avenue Oscar Lambret, CHRU de Lille, 59037 LILLE Cedex, France; e-mail: fgottrand@chru-lille.fr

This study was support by a grant from the French Minister of Health (Hospital Program for Clinical Research grant number 1998/1905). tory causes and the use of pulmonary medications after discharge during the first years of life (2).

Several studies have reported nutritional or pulmonary complications of BPD early in life, but little is known about these factors during long-term follow-up. To our knowledge, no study has assessed both nutritional and pulmonary outcomes in later childhood in children having BPD in infancy. We hypothesized that early life events during the neonatal period could influence long-term outcomes of children with $\mathrm{BPD}$, in particular the fixed pulmonary sequelae and undernutrition in later childhood. The objective of this study was to identify early risk factors associated with nutritional and respiratory outcomes in later childhood in children who experienced BPD as infants.

\section{SUBJECTS AND METHODS}

Children were selected from a single-center population of children with BPD born between 1994 and 1999. The study was performed from April 2002 to April 2003. Inclusion criteria were prematurity, BPD, and age $4-8$ y at the time of the study. Patients included 24-32 wk PMA premature infants. BPD was defined as an oxygen $(>21 \%)$ requirement for at least $28 \mathrm{~d}$ as oxygen therapy in babies born up to 36 wk PMA or babies born past 36 wk PMA discharged to home (2). Exclusion criteria were a recent acute infection lasting for $<15 \mathrm{~d}$, parental or patient refusal to participate in the study, and any malformation known to interfere with nutritional status (e.g. diaphragmatic hernia, congenital heart disease, and genetic disease). A sample of 52 children ( 22 girls, 30 boys) was selected out of 195 eligible patients. One hundred and forty-three eligible children were not included: 42 refused to participate, 60 were lost to follow-up, 5 moved to another region, 15 died, and 21 had associated malformations (16 diaphragmatic hernia, 5 cardiological malformations).

The perinatal characteristics were obtained by retrospective analysis of their neonatal files (gestational age, birth weight, length of the period of ventilation, length of oxygen therapy, patent ductus arteriosus, necrotizing enterocolitis, gastroesophageal reflux, intrauterine growth restriction, chorioamnionitis, duration of hospitalization, weight at discharge and at term, intraventricular hemorrhage, neurologic status at $2 \mathrm{y}$ of age, and tracheal stenosis). Socioeconomic status was taken as the level of education of the mother. Height and weight growth curves from birth to age $4-8$ y were also obtained. We carefully checked the medical charts of the 143 nonincluded children to confirm that they did not differ from the 52 children studied on

Abbreviations: BMD, bone mineral density; BPD, bronchopulmonary dysplasia; FFM, fat-free mass; FM, fat mass; FRC, functional residual capacity; PMA, postmenstrual age; R, resistance; REE, resting energy expenditure; $\mathrm{VCO}_{2}$, expired carbon dioxide flow; $\mathbf{V o}_{2}$, inspired oxygen flow 
socioeconomic level, neonatal characteristics (intrauterine growth restriction, gestational age, birth weight, chorioamnionitis), neurologic status (intraventricular hemorrhage and cerebral palsy at $2 \mathrm{y}$ of age), use of corticosteroid in the neonatal period, and initial evolution (oxygen therapy, mechanical ventilation, duration of hospitalization, weight at discharge, patent ductus arteriosus, first oral feeding, gastroesophageal reflux, tracheal stenosis, esophagitis, and neonatal ileus).

Before the study began, the purpose and objectives were carefully explained to the participants (children and parents). Written informed consent was obtained from parents and from children when appropriate. All procedures were performed in accordance with the ethical standards of the Helsinki Declaration of 1975, as revised in 1983, and French Good Clinical Practice (1987). This study was approved by the local ethical committee (Comité de Protection des Personnes pour la Recherche Biomédicale).

Nutritional status was evaluated using auxological characteristics (age, weight, height, head circumference) and dual x-ray absorptiometry (DXA). Body weight $(\mathrm{W})$ and height $(\mathrm{H})$ were measured without shoes and with light indoor clothing. A standard precision hospital scale was used for all measurements of body weight. Height was measured with a wall-mounted stadiometer. Body mass index (BMI) was calculated as weight (in kilograms) divided by height (in meters) squared. Growth measurements were converted to $Z$ scores relative to the French growth references of Sempé et al. (3). Z scores were computed by subtracting the predicted value for the child's age (for $Z$ scores reported by age) or for the child's height (for $Z$ scores for $\mathrm{W} / \mathrm{H}$ ) and sex from the child's measurement, and then dividing the difference by the $\mathrm{SD}$ of the measurement in the reference group as follows:

$$
Z=(\text { observed }- \text { predicted }) / S D
$$

The expected value for the measurement is 0 , and $2 \mathrm{SD}$ above this value estimates the 98th percentile and 2 SD below estimates the 2 nd percentile. Height and weight were corrected for gestational age until the age of $2 \mathrm{y}$. Children were divided in two groups according to their nutritional status. Undernutrition was defined as a $Z$ score for weight for height $2 \mathrm{SD}$ below the mean.

The DXA instrument was a Lunar DPX-IQ "pencil-beam" (Lunar Radiation Corporation, Madison, WI). The whole-body scan time was 560-590 s, and the radiation dose was $<0.3 \mu \mathrm{Sv}$. A tissue bar was scanned as the reference material. Total body image acquisition and analysis were obtained following the manufacturer's instructions. FM and FFM were calculated using the pediatric software provided by the manufacturer. BMD was also calculated, and the reference values used in the calculation of $Z$ scores for BMD were from an American source provided with the software.

REE was measured by indirect calorimetry, using the Deltatrac II opencircuit ventilated hood system (Datex Instrumentation Corporation, Helsinki, Finland). The respiration quotient and flow settings were calibrated by reference to alcohol combustion every $6 \mathrm{mo}$ and with a reference gas mixture $\left(95 \% \mathrm{O}_{2}, 5 \% \mathrm{CO}_{2}\right)$ before each measurement. $\left.\mathrm{VO}_{2}, \mathrm{VCO}_{2}\right)$, and respiration quotient were calculated. REE was calculated every minute from oxygen consumption ( $\mathrm{VO}_{2}$ in milliliters per minute) and production of carbon dioxide $\left(\mathrm{VCO}_{2}\right.$ in milliliters per minute) using the Weir formula without protein correction (4):

$$
\operatorname{REE}(\mathrm{kcal} / \mathrm{h})=\left(3.9 \times \mathrm{Vo}_{2}+1.1 \times \mathrm{VCO}_{2}\right) \times 1.44 / 24
$$

REE was measured after a fast of 10-12 h. After an adaptation period of 15 min under a transparent canopy, continuous respiratory exchange measurements were initiated (5). REE was measured for $30 \mathrm{~min}$.

Parents performed an alimentary inventory using a 7-d food questionnaire. Data were analyzed with BILNUT 3 software (Nutrisoft, Cerelles, France).

All pulmonary function tests were performed after bronchodilators had been stopped for at least 2 wk. Airway resistance (R) was measured by interruption of the airflow (software Dyn'R, Paris, France); seven measurements were performed. A variation $<14 \%$ was needed to validate the results. FRC was measured by the dilution of helium according to American Thoracic Society standards (Medisoft, Brussels, Belgium); this technique required two measurements with a variation of $<10 \%$ to validate the results. The spirometry-flow volume curve, area under the curve, and peak flow were evaluated. Five reproducible spirometry-flow volume curves $(<10 \%)$ were necessary to validate the data.

Values are expressed as the percentage of the predicted value normalized for height and sex. R $<150 \%$, FRC $<120 \%$, and peak flow $>120 \%$ were considered within the normal ranges. Obstruction airflow was defined as $\mathrm{R}>$ $150 \%$, and distension was defined as FRC $>120 \%$. We assumed a maximal expiratory flow-volume loop with a marked concavity to demonstrate distal flow limitation during spirometry. Measurements were repeated $20 \mathrm{~min}$ after $200 \mathrm{mg}$ of inhaled salbutamol. Reversibility of obstruction and hyperinflation was defined as a decrease of $10 \%$ of the FRC and $30 \%$ of the R. In the spirometry tests, reversibility was positive when the concavity disappeared and an increase of $>30 \%$ was observed in the area under the curve.

Univariate analyses were first performed to check and summarize the data (box plots, means, SD and percentiles for numerical parameters, and frequencies for qualitative parameters). The population was then divided into two groups: undernourished children $(Z \mathrm{~W} / \mathrm{H}<-2 \mathrm{SD})$ and children with normal nutritional status $(Z \mathrm{~W} / \mathrm{H} \geq-2 \mathrm{SD})$. The population was also classified according to its pulmonary status (obstruction versus no obstruction of the airways; hyperinflation versus no hyperinflation of the airways). Bivariate analysis was then performed to compare the groups. The Wilcoxon test was used for numerical parameters and the $\chi^{2}$ test or Fisher exact test, if needed, was used for qualitative parameters.

Finally, parameters that were significant at the $15 \%$ level in the bivariate analysis were entered into a stepwise logistic regression analysis to evaluate the most significant factors associated with undernutrition and abnormal pulmonary function. The evolution of the $Z$ score from term to $4 \mathrm{y}$ of age was assessed using nonparametric analysis of variance for repeated measurements. All statistical analysis was performed with the SAS Software. The significance level was set at 0.05 .

\section{RESULTS}

At the time of the study, 18 children with BPD were undernourished $(35 \%)$. Table 1 details the auxological characteristics and body composition of the population. Girls were more frequently undernourished than were boys (12 girls and 6 boys, $p=0.009$ ). FM, FFM, and ZBMD were significantly lower in the undernourished group than in the normally nourished group (Table 1).

The $Z$ scores of $\mathrm{W} / \mathrm{H}$ were calculated at term, and at ages 6 mo, $12 \mathrm{mo}, 24 \mathrm{mo}, 3 \mathrm{y}$, and $4 \mathrm{y}$. The nonparametric analysis of variance for repeated measurements showed that $Z$ scores were significantly lower at any age except term in the undernourished children compared with the normally nourished children (Fig. 1).

When expressed as an absolute value, REE was significantly lower in the undernourished group $(857 \pm 94 \mathrm{kcal} / \mathrm{d})$ than in the normally nourished group $(971 \pm 90 \mathrm{kcal} / \mathrm{d}, p<$ 0.01). However, because undernourished children have lower body weight and FFM, the REE expressed per kilogram of body weight or per kilogram of FFM was significantly higher in the undernourished group. REE per kilogram of body weight was $60 \pm 8 \mathrm{kcal} / \mathrm{kg} / \mathrm{d}$ in undernourished children and

Table 1. Body weight and body composition of undernourished and normally nourished children at the age of 4-8 y

\begin{tabular}{lccc}
\hline & $\begin{array}{c}\text { Normal } \\
\text { nutritional } \\
\text { status } \\
(n=34)\end{array}$ & $\begin{array}{c}\text { Undernutrition } \\
(n=18)\end{array}$ & $p$ Value* \\
\hline Age (y) & $6 \pm 1$ & $6 \pm 1$ & 0.9 \\
Weight (kg) & $19 \pm 3$ & $15 \pm 2$ & 0.04 \\
Height (m) & $112 \pm 7$ & $109 \pm 7$ & 0.4 \\
HC (cm) & $51 \pm 2$ & $48 \pm 2$ & 0.05 \\
BMI (kg/m $\left.{ }^{2}\right)$ & $15 \pm 2$ & $12 \pm 1$ & $<0.001$ \\
Z Weight/age (SD) & $-0.2 \pm 1.1$ & $-2.1 \pm 0.8$ & $<0.001$ \\
$Z$ Height/age (SD) & $-0.2 \pm 1.1$ & $-0.9 \pm 1.3$ & 0.4 \\
Z Weight/height (SD) & $-0.3 \pm 0.2$ & $-2.6 \pm 1$ & $<0.001$ \\
$Z$ HC & $-0.6 \pm 1.2$ & $-1.9 \pm 1.7$ & 0.04 \\
FFM (kg) & $15.5 \pm 2$ & $13.4 \pm 2$ & 0.04 \\
FM (\% of weight) & $16 \pm 8$ & $11 \pm 5$ & $<0.001$ \\
$Z$ BMD & $0.4 \pm 0.7$ & $-0.3 \pm 1.0$ & 0.01 \\
\hline
\end{tabular}

* Difference between undernourished and normally nourished children$($ mean $\pm \mathrm{SD})$. 


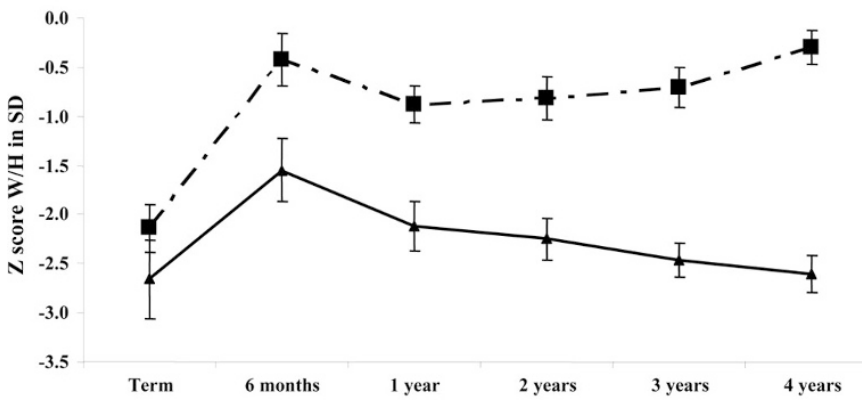

Figure 1. Differences in $Z$ scores of weight/height (SD) between undernourished $(\boldsymbol{\Lambda})$ and normally nourished $(\boldsymbol{\square})$ children from term to $4 \mathrm{y}(n=52)$. Time effect: $p<0.0001$; group effect: $p<0.0001$; interaction: $p<0.0001$.

$49 \pm 6 \mathrm{kcal} / \mathrm{kg} / \mathrm{d}$ in normally nourished children $(p=0.01)$. REE per kilogram of FFM was $78 \pm 10 \mathrm{kcal} / \mathrm{kg} \mathrm{FFM} / \mathrm{d}$ in undernourished children and $57 \pm 9 \mathrm{kcal} / \mathrm{kg} \mathrm{FFM} / \mathrm{d}$ in normally nourished children $(p=0.01)$. The energy intake and carbohydrate intake were significantly higher in the undernourished group $(2033 \pm 660 \mathrm{kcal} / \mathrm{d})$ than in the normally nourished group $(1800 \pm 568, p=0.01)$. Carbohydrate intake as a percentage of total energy intake was $59 \% \pm 7 \%$ in the undernourished children and $49 \% \pm 7 \%$ in the normally nourished children $(p=0.02)$. Energy intake remained significantly higher in the undernourished group than in the children with normal nutritional status when expressed relative to weight $(140 \pm 46 \mathrm{kcal} / \mathrm{kg} / \mathrm{d}$ versus $104 \pm 31 \mathrm{kcal} / \mathrm{kg} / \mathrm{d}$, $p=0.01)$ or relative to FFM $(155 \pm 52 \mathrm{kcal} / \mathrm{kg} \mathrm{FFM} / \mathrm{d}$ versus $103 \pm 45 \mathrm{kcal} / \mathrm{kg} \mathrm{FFM} / \mathrm{d}, p=0.04)$.

Thirty-one children (60\%) presented with abnormal lung function. At the time of the study, only one child was receiving inhaled steroids (fluticasone, $100 \mu \mathrm{g} / \mathrm{d}$ ) on a regular basis. None of the patients used bronchodilators at the time of the study or on a regular basis. Obstruction was present in 16 patients and was reversible in 7 children. Distension was diagnosed in 14 patients and was reversible in 4 . Forty-five patients cooperated fully in the spirometry tests: marked concavity was present in 21 of the 45 expiratory flow curves and reversibility was observed in 9 children. Five children had distension associated with obstruction (both distal and proximal), six had distension associated with distal obstruction, and six had both distal and proximal obstruction. Four of 14 patients with hyperinflation exhibited reversibility after salbutamol. Reversibility after salbutamol was also observed in 7 of 16 children with proximal obstruction and in 9 of 21 with distal obstruction. Pulmonary function test results did not differ significantly between the undernourished children and those with normal nutritional status (Table 2). However, the group with distal obstruction had significantly lower FFM (87\% versus $93 \%$ of FFM, $p=0.05$ ) and $Z$ scores for BMD $(-0.2 \pm 0.7$ versus $0.1 \pm 0.9, p=0.03)$. REE was significantly higher in children with distal obstruction $(970 \pm 100$ $\mathrm{kcal} / \mathrm{d}$ versus $933 \pm 90 \mathrm{kcal} / \mathrm{d}, p=0.03)$. In addition, distal obstruction and hyperinflation of the airways were significantly associated with intrauterine growth restriction (11/21 versus $8 / 21, p=0.04)$. The $Z$ scores for $\mathrm{W} / \mathrm{H}$ were significantly lower at the age of $2 \mathrm{y}$ in children who exhibited
Table 2. Lung function tests (\% of theoretic values)

\begin{tabular}{|c|c|c|c|}
\hline & $\begin{array}{c}\text { Normal } \\
\text { nutritional } \\
\text { status } \\
(n=34)\end{array}$ & $\begin{array}{l}\text { Undernutrition } \\
\quad(n=18)\end{array}$ & $p$ Value* \\
\hline FRC & $113 \pm 26$ & $110 \pm 17$ & 0.8 \\
\hline $\mathrm{FRC}\left(\right.$ post $\beta_{2}$ ) & $102 \pm 17$ & $100 \pm 15$ & 0.8 \\
\hline $\mathrm{R}$ & $147 \pm 37$ & $130 \pm 31$ & 0.1 \\
\hline $\mathrm{R}\left(\right.$ post $\left.\beta_{2}\right)$ & $124 \pm 29$ & $113 \pm 33$ & 0.8 \\
\hline Area (1) & $1.2 \pm 0.6$ & $1.3 \pm 0.7$ & 0.1 \\
\hline Area (post $\left.\beta_{2}\right)(2)$ & $1.7 \pm 0.7$ & $1.6 \pm 0.7$ & 0.1 \\
\hline Area $1 / 2$ & $137 \pm 32$ & $132 \pm 29$ & 0.7 \\
\hline Peak-flow & $84 \pm 21$ & $86 \pm 24$ & 0.8 \\
\hline Peak-flow (post $\beta_{2}$ ) & $96 \pm 20$ & $101 \pm 19$ & 0.6 \\
\hline
\end{tabular}

$\mathrm{R}$, resistance; Area, area under the spirometric curve $\left(\mathrm{L}^{2} / \mathrm{s}\right) ; \beta_{2}$, inhaled salbutamol.

* Difference between undernourished and normally nourished groups.

hyperinflation $(-1.6 \pm 1.7 \mathrm{SD}$ versus $-1.0 \pm 0.8 \mathrm{SD}, p=$ $0.05)$ or distal obstruction of the airways $(-1.7 \pm 1.4 \mathrm{SD}$ versus $-1.0 \pm 0.9 \mathrm{SD}, p=0.02$ ).

Lower gestational age was the only factor associated with undernutrition (Table 3). Several neonatal characteristics were significantly associated with abnormal pulmonary function tests: antenatal growth restriction, gestational age, and being a twin. Twins presented a significantly higher risk for developing pulmonary hyperinflation $(p=0.01)$. Antenatal growth restriction was associated with hyperinflation of the airways ( $p$ $=0.02$ ). Gestational age at birth was associated with a higher risk of developing hyperinflation in later childhood $(29 \pm 2$ wk PMA versus $27 \pm 1.6$ wk PMA, $p=0.006$ ).

Bivariate analysis showed that only four parameters were associated with undernutrition: sex, $Z$ score for head circumference, gestational age at birth, and $Z$ score for $\mathrm{W} / \mathrm{H}$ at $2 \mathrm{y}$ of age. A stepwise logistic regression performed on those four

Table 3. Neonatal characteristics (mean $\pm S D$ )

\begin{tabular}{|c|c|c|c|}
\hline & $\begin{array}{c}\text { Normal } \\
\text { nutritional } \\
\text { status } \\
(n=34)\end{array}$ & $\begin{array}{l}\text { Undernutrition } \\
\quad(n=18)\end{array}$ & $p$ Value* \\
\hline Birth weight (g) & $1047 \pm 309$ & $993 \pm 309$ & 0.5 \\
\hline Gestational age (wk) & $28.6 \pm 2$ & $27.5 \pm 1$ & 0.05 \\
\hline Weight at discharge $(\mathrm{g})$ & $2742 \pm 629$ & $2889 \pm 900$ & 0.1 \\
\hline Weight at term $(\mathrm{g})$ & $2422 \pm 488$ & $2124 \pm 609$ & 0.06 \\
\hline Hospitalization duration (d) & $116 \pm 103$ & $144 \pm 124$ & 0.1 \\
\hline Total ventilation (d) & $45 \pm 93$ & $45 \pm 41$ & 0.8 \\
\hline Tracheal intubation (d) & $38 \pm 37$ & $37 \pm 37$ & 0.7 \\
\hline $\begin{array}{l}\text { Continuous positive airway pressure } \\
\text { ventilation (d) }\end{array}$ & $8 \pm 10$ & $8 \pm 11$ & 0.8 \\
\hline Oxygen therapy duration (d) & $150 \pm 36$ & $169 \pm 37$ & 0.9 \\
\hline First oral feeding (d) & $24 \pm 13$ & $21 \pm 13$ & 0.9 \\
\hline Intrauterine growth restriction $(n)$ & 12 & 7 & 0.1 \\
\hline Maternal-fetal infection $(n)$ & 4 & 6 & 0.7 \\
\hline Twins $(n)$ & 7 & 3 & 0.8 \\
\hline Gastroesophageal reflux $(n)$ & 32 & 15 & 0.3 \\
\hline Esophagitis $(n)$ & 2 & 2 & 0.6 \\
\hline Neonatal ileus $(n)$ & 14 & 7 & 0.8 \\
\hline Patent ductus arteriosus $(n)$ & 26 & 10 & 0.1 \\
\hline Intraventricular hemorrhage $(n)$ & 18 & 6 & 0.4 \\
\hline $\begin{array}{l}\text { Neurological abnormalities at } \\
2 \text { y of age }(n)\end{array}$ & 13 & 4 & 0.07 \\
\hline
\end{tabular}

* Difference between undernourished and normally nourished groups. 
parameters showed that only two independent factors were significantly associated with undernutrition: under nutrition at the age of 2 y $[p<0.001$; odds ratio $(\mathrm{OR})=8.9 ; 95 \%$ confidence interval (CI), 2.2-36.4] and female sex $[p=0.03$; $\mathrm{OR}=4.5$ (95\% CI, 1.1-18.3)].

Bivariate analysis showed that only four parameters were associated with abnormal pulmonary function test: gestational age at birth, $Z$ score for $\mathrm{W} / \mathrm{H}$ at $2 \mathrm{y}$ of age, antenatal growth retardation, and twin birth). A stepwise logistic regression performed on those four parameters showed that the only independent factor significantly associated with hyperinflation of the airways was undernutrition at the age of $2 \mathrm{y}[p=0.05$; $\mathrm{OR}=1.2(95 \% \mathrm{CI}, 1.1-3.0)]$.

\section{DISCUSSION}

Rapid progress in the management of prematurity has contributed to an increase in survival of extremely premature infants $(6,7)$. These significant advances, especially the use of antenatal steroids and continuous positive airway pressure ventilation, have influenced pulmonary outcome and tracheal sequelae $(6,7)$. Although our study suggests that nutritional outcomes in infancy have not changed, undernutrition remains a frequent feature in the preterm population. Considering the recent advances in neonatal care, it is difficult to compare current results in children with BPD with previously published studies. A few studies have reported nutritional status during long-term follow-up of patients with BPD (8-10), although most were published more than $6 \mathrm{y}$ ago and therefore address historical forms of BPD. In preterm infants without BPD, catch up of height and weight usually occurs before the age of $2 \mathrm{y}$ and only 5-10\% present with growth retardation after the age of 2 y (11-13). Conversely, preterm children who develop BPD usually show impaired growth early in life, which persists for years $(2,7,9)$. Our study shows that undernutrition involves different body compartments (e.g. FM, FFM, BMD) and is associated with a smaller head circumference compared with normally nourished children. Undernutrition is also associated with elevated REE, despite the high energy intake. Our results demonstrating that long-term undernutrition originates from the first months of life suggest that the neonatal period is crucial for the future nutritional status of infants with BPD.

One surprising result was that girls were undernourished more frequently than were boys. This difference in nutritional status between girls and boys has not been reported previously. However, our results are consistent with two previous randomized trials on nutritional intervention in preterm infants that showed a sex difference in the effect of diet, which was greater in boys than in girls $(12,13)$. Cooke et al. (12) examined the changes over the whole body during dietary intervention in preterm infants at six and 12 mo after hospital discharge, and found that only boys gained significant body weight. Carver et al. (13) studied a group of 125 preterm infants receiving a nutrient-enriched formula at six and 12 mo after discharge. The nutrient-enriched formula increased growth mainly in children with birth weight $<1250 \mathrm{~g}$ and in boys (13). These two studies suggest that that the sex of preterm infants influences the postdischarge responsiveness to nutrient supplementation. We have no clear explanation for such a difference.

Lung sequelae are frequent events in children with BPD (14), who usually experience pulmonary infections and hyperreactivity until the age of $2 \mathrm{y}$ (14). Lung pulmonary tests at school age usually demonstrate obstruction, hyperinflation, and hyperreactivity of the airways (14-16), and $60 \%$ of the children in our study demonstrated one of more of these dysfunctions. Hyperinflation seems to be related to a fixed lesion that does not progress with time and reflects gas trapping in the distal airways (14). Hyperinflation of the airways is a more specific sequel of BPD than obstruction of the airways and could be related to asthma (14).

The main objective of our study was to identify early risk factors in infancy for undernutrition or lung sequelae in later childhood. The cross-sectional study design could show only an association of early neonatal events with nutritional and pulmonary status between the ages of 4 and $8 \mathrm{y}$, and cannot assess any causality underlying this relationship. Multivariate analysis showed that undernutrition at 4-8 y of age was not associated with neonatal events. Our results did not confirm those of previous studies showing that neonatal factors such as patent ductus arteriosus, chorioamnionitis, gastroesophageal reflux, delayed oral nutrition, prolonged hospitalization, or cerebral abnormalities (cerebral palsy or periventricular leukomalacia) contribute to growth failure $(15,16)$. However, the earlier studies were performed only during the first months of life and did not relate to growth velocity in later childhood.

A number of neonatal factors, such as baro- and volutrauma, oxygen toxicity, and prolonged hospitalization can affect the immature pulmonary systems of preterm newborn infants (6), but were not associated with lung sequelae in later childhood in our study. One limitation of our study is that only $25 \%$ of the eligible population with BPD was studied because we could not obtain information on neonatal characteristics, neurologic status, steroid use during the neonatal period, and initial evolution in neonatal care unit of all 195 children. Although we cannot exclude the possibility of a selection bias, the children who were not included did not differ from the 52 children studied in regards to the severity of their disease and neonatal characteristics. We tried to limit all other bias by studying a single-center cohort treated by the same experienced team of neonatologists.

Family history of atopy, childhood respiratory illness, passive exposure to cigarette smoke, steroid therapy, and recurrent infection are important confounding factors for lung function or growth in children $(15,16)$. We included only early postnatal systemic steroids, but this was not significantly associated with long-term pulmonary outcome. Socioeconomic status can also influence growth (15). We evaluated socioeconomic status by the level of maternal education, but found no significant difference between the groups.

The most interesting finding is that undernutrition before $2 \mathrm{y}$ of age is an independent factor associated with both hyperinflation of the airways and undernutrition in later childhood, despite the lack of a direct relationship between pulmonary function and nutritional status at age 4-8 y. Our data 
suggest that undernutrition in later childhood does not result from low energy intake but from an abnormal energy balance and a persistent increase in REE. REE was also positively associated with abnormal pulmonary function (hyperinflation or obstruction of the airways) at age 4-8 y. REE is associated with respiratory status because of an increased oxygen consumption of respiratory muscles secondary to an increased resistive load in the neonatal period (17). Our data show that this pattern persists at the long-term follow-up and may explain the persistence of undernutrition with time.

Our data also show that undernutrition is not correlated with pulmonary status in later childhood, but that both are associated with nutritional status before the age of $2 \mathrm{y}$. After this period, undernutrition and hyperinflation of the airways seem to be fixed sequelae and independent features. In children who had BPD in infancy, nutritional status at $2 \mathrm{y}$ of age could influence both nutrition and pulmonary outcomes in childhood. If this hypothesis is confirmed, early randomized nutritional intervention should be performed before the age of $2 \mathrm{y}$ to prevent lung sequelae and undernutrition in later childhood.

\section{REFERENCES}

1. Northway WH, Rosan RC, Porter DY 1967 Pulmonary disease following respiratory therapy of hyaline membrane disease-bronchopulmonary dysplasia. N Engl J Med 276:357-368

2. Jobe AH, Bancalari E 2001 Bronchopulmonary dysplasia. Am J Respir Crit Care Med 163:1723-1729
3. Sempé M, Pedron G, Roy-Pernot MP 1979 Auxologie: méthodes et séquences. Theraplix, Paris

4. Weir JB 1949 New methods for calculating metabolic rate with special reference to protein metabolism. J Physiol 109:1-9

5. Simonson DC, DeFronzo RA 1990 Indirect calorimetry: methodological and interpretative problems. Am J Physiol 258:E399-E412

6. Lui K, Lloyd J, Ang E, Rynn M, Gupta JM 2000 Early changes in respiratory compliance and resistance during the development of bronchopulmonary dysplasia in the era of surfactant therapy. Pediatr Pulmonol 30:282-290

7. Bancalari E, Wilson-Costello D, Iben S 2005 Management of infants with bronchopulmonary dysplasia in North America. Early Hum Dev 81:171-179

8. Vrlenich LA, Bozynski ME, Shyr Y, Schork MA, Roloff DW, Mc Cormick MC 1995 The effect of bronchopulmonary dysplasia on growth at school age. Pediatrics 95:855-859

9. Weiler HA, Paes B, Shah JK, Atkinson SA 1997 Longitudinal assessment of growth and mineral accretion in prematurely born infants treated for chronic lung disease with dexamethasone. Early Hum Dev 47:271-286

10. Markestad T, Fitzhardinge PM 1981 Growth and development in children recovering from bronchopulmonary dysplasia. J Pediatr 98:597-602

11. Lucas A, Fewtrell MS, Morley R, Singhal A, Abbott RA, Isaacs E, Stephenson T, MacFadyden UM, Clements H 2001 Randomized trial of nutrient-enriched formula versus standard formula for postdischarge preterm infants. Pediatrics 108:703-11

12. Cooke RJ, McCormick K, Griffin IJ, Embleton N, Faulkner K, Wells JC, Rawlings DC 1999 Feeding preterm infants after hospital discharge: effect of diet on body composition. Pediatr Res 46:461-464

13. Carver JD, Wu PY, Hall RT, Ziegler EE, Sosa R, Jacobs J, Baggs G, Auestad N, Lloyd B 2001 Growth of preterm infants fed nutrient-enriched or term formula after hospital discharge. Pediatrics 107:683-689

14. Filippone M, Sartor M, Zachello F, Baraldi E 2003 Flow limitation in infants with bronchopulmonary dysplasia and respiratory function at school age. Lancet 361:753-754

15. Khan N, Jamal M 2003 Maternal risk factors associated with low birth weight. J Coll Physicians Surg Pak 13:25-28

16. Doyle LW, Halliday HL, Ehrenkranz RA, Davis PG, Sinclair JC 2005 Impact of postnatal systemic corticosteroids on mortality and cerebral palsy in preterm infants: effect modification by risk for chronic lung disease. Pediatrics 115:655-661

17. De Meer K, Westertep KR, Houwen RH, Brouwers HA, Berger R, Okken A 1997 Total energy expenditure in infants with bronchopulmonary dysplasia is associated with respiratory status. Eur J Pediatr 156:299-304 